\title{
REFORMAS CONSTITUCIONALES POSIBLES Y REFORMAS CONSTITUCIONALES IMPOSIBLES. NOTAS PREVIAS A LA REFORMA DE LA CONSTITUCIÓN
}

\author{
JAVIER GARCÍA FERNÁNDEZ \\ Catedrático de Derecho constitucional \\ Universidad Complutense de Madrid
}

\begin{abstract}
SUMARIO
I. Introducción.

II. Entre una reforma constitucional fracasada y una reforma constitucional imprevista. I. El fracaso.

III. Entre una reforma constitucional fracasada y una reforma constitucional imprevista. II. Lo imprevisto.

IV. ¿Se ha abierto la posibilidad real de una reforma de la Constitución?
\end{abstract}

\section{INTRODUCCIÓN}

A finales del siglo XIX decía Charles Bourgeaud describía la Constitución británica con estas palabras: "Elle est perpétuellement en voie de formation. C'est une barrière que fléxit sous la pression des circonstances, quand cette pression atteint un certain degree d'intensité, mais une barrière quine rompt pas...» ${ }^{1}$.

La cita viene a cuento porque la octava y la novena legislaturas de las Cortes Generales, a diferencia de las anteriores (y con la excepción de la cuarta en la que tuvo lugar la

1 Charles BOURGEAUD: Établissement et revision des constitutions en Amérique et en Europe, Thorin et Fils Éditeurs, París, 1893, pág. II. 
reforma del artículo 13.2 de la Constitución), han conocido cierto movimiento de reforma constitucional, en parte fracasado y en parte triunfante, de modo que la Constitución ha cedido ante una intensa presión pero al mismo tiempo ha sido una barrera que se resistía al cambio. Pero el fracaso de la reforma constitucional anunciada en el programa electoral del PSOE de 2004 y la rapidísima reforma de septiembre de 2011 tienen algo en común: ¿vendría a dar la razón a lo que hace muchos años anunció Loewenstein ${ }^{2}$, a la ruptura o superación del paradigma formado por la contraposición rigidez/flexibilidad constitucional?Esa contraposición nació, como se sabe, con Bryce como una dicotomía consuetudinaria/estatutaria ${ }^{3}$ pero acabó derivando hacia una calificación fundada en la mayor o menor facilidad de reforma de la Constitución de cuño estatutario, como señaló Wheare que apuntó que los términos de Bryce inducen a error porque la mayor o menor dificultad de reforma de una Constitución se residencia, salvo en unos pocos casos, en la complejidad de reforma de un texto constitucional escrito, no consuetudinario ${ }^{4}$. Sin embargo, como bien ha recordado Garrorena, la rigidez constitucional permite que una Constitución no abdique de la supralegalidad y tenga esa condición como elemento definitorio de su naturaleza jurídica en el campo de las fuentes del Derechos.

Evidentemente, en el ordenamiento español la rigidez constitucional está claramente regulada ${ }^{6}$ pero viendo el fracaso de la reforma constitucional de la octava legislatura y la rapidez con que se reformó la Constitución en 2011 es obligado pensar que en España la reforma constitucional es, más que un procedimiento jurídico para asegurar la primacía del poder constituyente, una posibilidad política a la que se accede o se rechaza en virtud de la conjunción de circunstancias políticas muy coyunturales, no jurídicas, que se compendian en el acuerdo o desacuerdo de los dos principales partidos nacionales. El carácter bifronte de la reforma constitucional, del que habla Garrorena, que permite la estabilidad y la adaptación al cambio, ${ }^{7}$ se transmuta, en la actualidad, como trataremos de explicar, en otra bifrontalidad: la Constitución se reforma, no por consideraciones de técnica jurídica (que evidentemente comportan una opción política innovadora) sino por consideraciones políticas autónomas, ajenas al Derecho.

2 Karl LOEWENSTEIN: Teoría de la Constitución (trad. A. Gallego Anabitarte), Ariel, Barcelona, 1976, $2^{\circ}$ ed., pág. 177.

3 James BRYCE: Constituciones flexibles y Constituciones rígidas (1901), Centro de Estudios Constitucionales, Madrid, 1988, págs. 9-11 (esta versión no indica traductor y tampoco señala qué edición es dentro del órgano que la editó si bien ya en 1962 el Instituto de Estudios Políticos publicó una segunda edición de esta obra.)

4 K. C. WHEARE: Las Constituciones modernas (trad. F. Morera y A. Alandi), Labor, Barcelona, 1971, pág. 21 .

5 Ángel GARRORENA MORALES: Derecho Constitucional. Teoría de la Constitución y sistema de fuentes, Centro de Estudios Políticos y Constitucionales, Madrid, 2011, págs. 98-101. Véanse también los trabajos de Alessandro PACE y Joaquín VARELA SUANZES recogidos en La rigidez de las Constituciones escritas (trad. P. Biglino Campos y L. Delgado del Rincón), Centro de Estudios Constitucionales, Madrid, 1995

6 Véanse Pedro de VEGA: La reforma constitucional y la problemática del poder constituyente, Tecnos, Madrid, 1985, págs. 128-175; y Javier PÉREZ ROYO: «De la reforma constitucional. Comentario introductorio al Título X», en Óscar ALZAGA VILLAAMIL (dir.): Comentarios a la Constitución de 1978, Cortes Generales -Editoriales de Derecho Reunidas, Madrid, 1999, t. XII, págs. 413-436.

7 Ángel GARRORENA MORALES: Derecho Constitucional. Teoría de la Constitución y sistema de fuentes cit., págs. 97-98. 
Decía Kelsen que una Constitución, por difícil que sea su reforma, es continuamente renovada para ponerla de acuerdo con las necesidades del tiempo y aunque no es fenómeno específico de las Constituciones, sino de todo el campo del Derecho, lo cierto es que el manejo de las normas constitucionales va variando paulatina e incansablemente de modo que se atribuyen a los términos primitivos un sentido que no es el originario y se va formando una práctica constitucional en contradicción con el texto inicial ${ }^{8}$. Naturalmente, Kelsen apuntaba a un fenómeno que se empezaba a conocer entonces que es el de las mutaciones constitucionales y ese fenómeno se da en la Constitución española.

Por eso en estas notas trataré de extraer algunas conclusiones jurídicas y políticas de los dos intentos de reforma para obtener a continuación alguna conclusión de lege ferenda.

\section{ENTRE UNA REFORMA CONSTITUCIONAL FRACASADA Y UNA REFORMA CONSTITUCIONAL IMPREVISTA. I. EL FRACASO}

En la campaña electoral previa a las elecciones de 14 de marzo de 2004 uno de los partidos concurrentes, el PSOE, llevaba en su programa la reforma de la Constitución. Pocas semanas después, el candidato socialista a la investidura, José Luis Rodríguez Zapatero, incorporó a su discurso un ofrecimiento a todas las fuerzas políticas para reformar la Constitución en los siguientes puntos: reforma del Senado, reglas de sucesión a la Corona, reconocimiento de las Comunidades Autónomas y Ciudades Autónomas en el texto constitucional y referencias a la Constitución europea que entonces se estaba tramitando 9 . Ese mismo día, el Portavoz del Grupo Parlamentario Popular y Presidente del Partido Popular, Mariano Rajoy, acogió la propuesta con muchas reticencias y con muy poco ánimo de colaboración ${ }^{10}$.

No es el lugar de narrar la historia de aquel intento de reforma que está bien descrito por Belda Pérez-Pedrero ${ }^{11}$. Pero sí conviene recordar tres hitos en el intento de reforma. En primer lugar, pocas semanas después de formarse el Gobierno de Rodríguez Zapatero se remitió al Congreso de los Diputados un proyecto de Ley Orgánica que dio lugar a la LO 3/2004, de 28 de diciembre, de reforma de la Ley Orgánica 3/1980, de 22 de abril, del Consejo de Estado. En esta reforma se previó expresamente que el máximo órgano consultivo habría de ser consultado en Pleno sobre «anteproyectos de reforma constitucional cuando la propuesta no haya sido elaborada por el propio Consejo de Estado» (artículo 21.1). Para el cumplimiento de estas funciones se creó una Comisión de Estudios y la disposición adicional de la Ley Orgánica 3/2004, de 28 de diciembre, previó que el Presidente del Consejo podría encomendar al Centro de Estudios Políticos y Constitucionales la realización de estudios e informes. Obviamente, la reforma del artículo 21.1 era innecesaria y perturbadora pues hacía del órgano consultivo o bien un pro-

8 Hans KELSEN: Teoría General del Estado (trad. L. Legaz Lacambra), Editora Nacional, México, D. F., 1979, págs. 331-332.

9 DSCD. Pleno y Comisión Permanente. VIII Legislatura. $\mathrm{N}^{\circ} 2.2004$. Sesión plenaria $\mathrm{n}^{\circ} 2$ celebrada el jueves 15 de abril de 2004, págs. 18-19.

10 DSCD, cit. (15 de abril de 2004), págs. 26-27.

11 Enrique BELDA PÉREZ-PEDRERO: La fallida reforma de la Constitución española durante la VIII Legislatura (2004-2008), Thomson Civitas, Cizur Menor (Navarra), 2008. 
motor de la reforma (que no es su función) o un coadyuvante de Derecho necesario de la iniciativa gubernamental de reforma, lo que no parece deba ser obligatorio, máxime cuando el incumplimiento del requisito no comportaría, posiblemente, la nulidad de la iniciativa gubernamental ${ }^{12}$.

El segundo hito, jurídicamente conectado al primero, fue el Acuerdo del Consejo de Ministros de 4 de marzo de 2005 por el que, en aplicación del artículo 21.1 de la Ley Orgánica del Consejo de Estado, se solicitó de éste un Informe sobre la reforma constitucional con el mismo alcance que había planteado el candidato Rodríguez Zapatero en su discurso de investidura ${ }^{13}$. Como dice Luis María Díez-Picazo, en lugar de presentar el proyecto de reforma constitucional, el Gobierno acudió a un órgano consultivo ${ }^{14}$. No es gratuita la sorpresa pero este proceder se debe probablemente a varios factores: i) una concepción muy «republicana» que quiere desplazar a la sociedad lo que debe ser competencia del Gobierno; y ii) el rápido descubrimiento de la frialdad del Partido Popular y el intento, quizá poco realista, de verse avalado por el Consejo de Estado.

El informe tardó once meses en emitirse pues si bien lleva fecha de enero de 2006 no fue aprobado por el Pleno hasta mediados de febrero. Ni las cuestiones planteadas por el Gobierno eran tan complejas ni las respuestas del Informe se caracterizaban por su densidad dogmática (por lo demás, eran correctas y muy académicas). El informe, además, fue publicado conjuntamente por el Consejo de Estado y su coadyuvante, el Centro de Estudios Políticos y Constitucionales. La publicación estaba dirigida por los Directores de ambos órganos ${ }^{15}$ e iba acompañado de veinticinco estudios doctrinales de una calidad alta y políticamente muy plurales (aunque excluyendo sectariamente a algunas «escuelas» del Derecho constitucional). El informe era un texto concienzudo, como es habitual en el Consejo de Estado, muy «académico» y hasta «técnico» (con propuestas de redacción de artículos) pero de menor alcance político salvo en los temas autonómicos. Así debía ser, dado el contenido material de la reforma propuesta por el Gobierno que no era particularmente conflictivo, salvo en la reordenación del Senado, por lo que dogmáticamente no debería haber suscitado grandes polémicas ${ }^{16}$.

12 En el mismo sentido, Ángel J. SÁNCHEZ NAVARRO: «La función constitucional del Consejo de Estado tras su reforma por la Lo 3/2004», Revista de Administración Pública, no 169, enero-abril 2006, págs. 353-382. Y del mismo autor, «El Consejo de Estado y la reforma constitucional», Revista de Derecho Político, $n^{\circ} 71-72$, enero-agosto 2008, págs. 517-550.

13 Véase Manuel PULIDO QUECEDO: «El inicio de la reforma constitucional (sobre el documento del Gobierno)», Repertorio Aranzadi del Tribunal Constitucional, $\mathrm{n}^{\circ}$ 1, primera quincena 2005, págs. 9-12.

14 Luis María DÍEZ-PICAZO: «Prólogo» a Enrique BELDA PÉREZ-PEDRERO: La fallida reforma de la Constitución española durante la VIII Legislatura (2004-2008) cit., pág. 15.

15 Francisco RUBIO LLORENTE y José ÁLVAREZ JUNCO (eds.): Informe del Consejo de Estado sobre la reforma constitucional. Texto del informe y debates académicos, Consejo de Estado-Centro de Estudios Políticos y Constitucionales, Madrid, 2006. Este volumen se complementa con el de José María MARTÍN OVIEDO: «Presentación del Informe del Consejo de Estado sobre la reforma de la Constitución», Revista Española de la Función Consultiva, $\mathrm{n}^{\circ} 4$, julio-diciembre 2005, págs. 19-24.

16 En apoyo de la reforma, en 2004 el Ministerio de Justicia dedicó las Jornadas anuales de la Abogacía General del Estado al mismo tema:La reforma constitucional. XXVI Jornadas de estudio de la Abogacía General del Estado, Ministerio de Justicia, Madrid, 2005. 
El tercer hito, bien que de efecto mucho más limitado, fue el renacimiento del interés de la doctrina por la reforma que se expresó en algún número monográfico de revistas ${ }^{17}$ y en alguna obra colectiva ${ }^{18}$.

Pero al concluir la octava legislatura, el Gobierno había perdido el impulso reformador y ya no se volvió a hablar de la reforma. Tres motivos, a mi entender, explican principalmente el fracaso: i) la actitud del Partido Popular ante la reforma; ii)las consecuencias del procedimiento de reforma, es decir, la obligada disolución de las Cortes y la necesariedad de referéndum al afectar la reforma al Título II de la Constitución; iii) la coincidencia del debate con la reforma del Estatuto de Cataluña.

i) La actitud del Partido Popular ante la reforma. No es el momento de recordar que la reforma constitucional en nuestros días ha perdido en buena medida la carga problemática que tuvo en el pasado cuando no existía el control de constitucionalidad de las Leyes que deriva de la naturaleza normativa de la propia Constitución. Los ejemplos alemán, italiano y francés nos muestran que en la reforma constitucional no se suscita el problema político de los límites de la reforma ${ }^{19}$ sino el mero problema de la adecuación del ordenamiento (expresado en su cabeza) a las necesidades de sociedades muy dinámicas y cambiantes ${ }^{20}$. Si examinamos la reforma que el Gobierno pidió informar al Consejo de Estado, es evidente su carácter jurídica y políticamente mesurado, asumible, en abstracto, por el Partido Popular. Pero, como vimos, el Presidente del Partido Popular respondió con reticencias a la inicial propuesta del candidato Rodríguez Zapatero en el debate de investidura.

Aunque pueda parecer poco ortodoxo en un trabajo jurídico, creo que es el momento de recordar una idea de Delphine Dulong, profesora de la Universidad de la Sorbona: la Constitución funciona como punto de coordinación de la acción de los profesionales de la

17 Parlamento y Constitución, nº 8, 2004; y Revista Española de la Función Consultiva, ${ }^{\circ}$ 4, julio-diciembre 2005. Esta última revista comenta además el Informe del Consejo de Estado. Precisamente, cuando se conoció la propuesta electoral del P.S.O.E., Claves de Razón Práctica, no 138, diciembre 2003, publicó tres artículos de Gregorio PECES-BARBA, Javier PÉREZ ROYO y José Luis CASCAJO CASTRO titulados respectivamente «La Constitución y la seguridad jurídica», «La aversión a la reforma constitucional» y «Constitución e interpretación constitucional» (págs. 4-23).

18 Santiago A. ROURA GÓMEZ y Javier TAJADURA TEJADA (dirs.): La reforma constitucional: la organización territorial del Estado, la Unión Europea y la igualdad de género, Biblioteca Nueva, Madrid, 2005. Más tardía, y fuera de la discusión de la reforma que se daba por fracasada: La reforma constitucional: ¿Hacia un nuevo pacto constituyente? Actas de las XIV Jornadas de la Asociación de Letrados del Tribunal Constitucional, Centro de Estudios Políticos y Constitucionales-Tribunal Constitucional, Madrid, 2009, con estudios de Ramón PUNSET BLANCO, Francisco RUBIO LLORENTE, Francesc de CARRERAS SERRA y Gurutz JÁUREGUI.

19 Sobre el tema de los límites a la reforma constitucional, Pedro de VEGA: La reforma constitucional y la problemática del poder constituyente cit., págs. 217-303; Enrique BELDA PÉREZ-PEDRERO: «Los límites a la reforma constitucional ante propuestas más propias de una revolución», Teoría y Realidad Constitucional, $\mathrm{n}^{\circ} 29,1^{\circ}$ semestre 2012, págs. 261-288; Paolo BISCARETTI DI RUFFIA: Introducción al Derecho constitucional comparado. Las «formas de Estado» y las «formas de gobierno. Las Constituciones modernas (trad. H. Fix-Zamudio), Fondo de Cultura Económica, México, D. F., 1996, págs. 555-560; Jorge Reinaldo A.VANOSSI: Teoría constitucional, Depalma, Buenos Aires, 2000, vol. I, págs. 173-276; Konrad HESSE: «Límites de la mutación constitucional», en sus Escritos de Derecho Constitucional (trad. P. Cruz Villalón), Centro de Estudios Constitucionales, Madrid, 1992, $2^{a}$ ed., págs. 79-104; e Ignacio COLOMBO MURÚA: Limites a las reformas constitucionales, Ed. Astrea, Buenos Aires, 2011.

20 Véase, para más detalles, Javier PÉREZ ROYO: La reforma de la Constitución, Congreso de los Diputados, Madrid, 1987, págs. 71-120. 
política, de manera que muchas acciones políticas están condicionadas por la anticipación que un actor puede hacer, adelantándose a lo que puedan formular sus adversarios ${ }^{21}$.

Un programa de reforma constitucional, por mesurado que sea, por mucho que se mueva dentro de lo que Lucas Verdú denominó la fórmula política de la Constitución $^{22}$, comporta, más allá de lo jurídico, un doble triunfo político para los promotores de la reforma. Triunfo político, en primer lugar, porque la reforma, por moderada, que sea, se residencia en los medios de comunicación y su impulsor (Gobierno, unos o varios partidos) se sitúa mediáticamente en el centro del debate. Y triunfo político, en segundo lugar, porque el impulsor de la reforma aparece ante los ciudadanos como el autor de una decisión política que ha sido capaz de hacer triunfar.

Quiere ello decir que, salvo momentos de extrema tensión política donde la reforma constitucional puede ser un elemento relevante del programa electoral de un partido, una reforma electoral no debe residenciarse en un programa electoral ni en un programa de investidura. Y no debe residenciarse porque ambas sedes politizan la reforma hasta hacerla inasumible por el principal partido de la oposición con independencia del contenido concreto de lo que se desea reformar. La reforma de la Constitución, como se dijo en los debates de la Constitución francesa de 1791, es una necesidad presumible en toda Constitución $^{23}$, pero ningún partido cede el protagonismo de la operación al adversario y menos aún admite, salvo crisis inminente, no poder participar en el diseño de la operación. Por eso el Partido Popular no apoyó la propuesta del candidato Rodríguez Zapatero en el debate de investidura de 2004 ni tampoco en la preparación subsiguiente de la reforma: estaba diseñada en todo su alcance por el Gobierno y poco margen de propuesta le quedaba. Y esa cualidad inicial no se subsanó, a juicio del Partido Popular, ni con la participación políticamente neutra del Consejo de Estado ni con el seminario de expertos organizado por el Centro de Estudios Políticos y Constitucionales aun cuando en el mismo participaran profesionales próximos al principal partido de la oposición. Y como decía Wilhelm Grewe, dado que los intereses de los partidos como grupos organizados dominan la política actual ${ }^{24}$, no hay que extrañarse de que una reforma constitucional ponderada, nada ideológica, fuera rechazada por el principal partido de la oposición cuyos intereses como partido y como oposición le impulsaban a salirse del juego establecido por el Gobierno.

En conclusión, una reforma constitucional de contenido poco partidista, asumible en un porcentaje alto por muchos partidos y sin duda por el Partido Popular no se llevó a cabo, principalmente, por un equivocado enfoque táctico del partido del que salió la ini-

21 Delphine DULONG: «Les institutions politiques», en Antonin COHEN, Bernard LACROIX y Philippe RIUTORT (dirs.): Nouveau Manuel de Science Politique, La Découverte, París, 2009, págs. 360-361.

22 Pablo LUCAS VERDÚ: «Artículo $1^{\circ}$. Estado social y democrático de Derecho», en Óscar ALZAGA VILLAAMIL (dir.): Comentarios a la Constitución de 1978cit, Madrid, 1996, t. I, págs. 100-101 y 104. Véase también Raúl CANOSA USERA: Interpretación constitucional y fórmula política, Centro de Estudios Constitucionales, Madrid, 1988, págs. 249-310.

23 Intervención del Diputado N. T. Frochotel el 31 de agosto de 1791, apud Roberto L. BLANCO VALDÉS: El valor de la Constitución, Alianza Ed., Madrid, 1994, pág. 255.

24 Wilhelm GREWE: «Lucha política por el poder y el bien común», en Kurt LENK y Franz NEUMANN (eds.): Teoría y sociología críticas de los partidos políticos (trad. I. de Otto), Anagrama, Barcelona, 1980, pág. 366. Véase también Richard ROSE: The Problem of Party Government, Penguin Books, Harmondsworth, 1976, págs. 290-299. 
ciativa. No podía incorporarse al programa electoral versus el programa electoral del otro gran partido nacional. No podía incorporarse en el programa del investidura salvo que ese punto se hubiera acordado minuciosamente con el principal partido de la oposición a fin de que en la réplica el Portavoz opositor respondiera con su apoyo. Y, en fin, no se debió formalizar el contenido al solicitar informe al Consejo de Estado (con ideas directrices incluidas) sin el previo acuerdo con la oposición. Ello demuestra que los debates sobre el endurecimiento o la flexibilidad de los procedimientos de reforma, siendo jurídicamente necesarios, sólo suelen cobrar sentido a posteriori, tras la decisión política de aplicar la reforma. Bien es cierto que en este caso hubo un óbice procedimental de cierta importancia que también contribuyó al fracaso de la reforma.

ii) Las consecuencias del procedimiento de reforma, es decir, la necesaria disolución de las Cortes y la necesariedad de referéndum al afectar la reforma al Título II de la Constitución. Todos los puntos de la reforma que el Gobierno remitió para informe al Consejo de Estado se podían tramitar a través del procedimiento establecido en el artículo 167 de la Constitución, salvo el punto relativo a «La supresión de la preferencia del varón en la sucesión al trono» que, siendo también revisión parcial, habría de tramitarse por el procedimiento del artículo 168 de la Constitución por afectar a su Título II.

Como es sabido, las consecuencias de una reforma conforme al artículo 168 son la disolución inmediata de las Cortes que han aprobado el principio de revisión y el sometimiento de la reforma a referéndum ${ }^{25}$, procedimiento sin duda bastante disuasorio ${ }^{26}$ por lo que ambas circunstancias, con alcance distinto, contribuyeron al fracaso de la reforma. En lo que se refiere a la disolución de las Cámaras que aprueban inicialmente la reforma, conforme al apartado 1 del citado artículo 168, es obvio que en todo el Derecho comparado constituye uno de los obstáculos más potentes a una reforma ${ }^{27}$. Sin embargo, ese obstáculo, aparentemente tan formidable, no era difícil de soslayar pues bastaba con acordar con la oposición aprobar la reforma justo antes de disolver las Cortes.

Mayor complicación política suscita el referéndum de ratificación de la reforma que ha previsto el apartado 3 del artículo 168. Y aquí estamos ante un problema político fáctico, no jurídico. Aunque en la octava legislatura no se habían dado los acontecimientos que a lo largo de 2012 han afectado a la imagen de la Corona, de su titular y, en general, de la Familia Real, en los dos partidos nacionales mayoritarios ha habido, de consuno, un cierto temor a que un referéndum sobre la regulación jurídica de este órgano constitucional, aunque incida en un aspecto no fundamental, dé lugar a campañas políticas que pongan en cuestión la forma política del Estado.

25 Véase, por todos, Javier PÉREZ ROYO: «Artículo 168. La revisión de la Constitución», en Óscar ALZAGA VILLAAMIL (dir.): Comentarios a la Constitución de 1978 cit., t. XII, págs. 483-505. Son interesantes las consideraciones del Informe del Consejo de Estado en Francisco RUBIO LLORENTE y José ÁLVAREZ JUNCO (eds.): Informe del Consejo de Estado sobre la reforma constitucional. Texto del informe y debates académicos cit.

26 También señala lo excesivamente disuasorio que es el procedimiento del artículo 168 Luis María DÍEZ-PICAZO: «Prólogo» cit., pág. 14.

27 Sobre antecedentes y Derecho comparado de los procedimientos de reforma, véase el Informe del Consejo de Estado en Francisco RUBIO LLORENTE y José ÁLVAREZ JUNCO (eds.): Informe del Consejo de Estado sobre la reforma constitucional. Texto del informe y debates académicos cit. A pesar de su antigüedad, tienen todavía interés Karl LOEWENSTEIN: Teoría de la Constitución cit., págs. 175-199; y Paolo BISCARETTI DI RUFFIA: Introducción al Derecho constitucional comparado. Las «formas de Estado" y las «formas de gobierno. Las Constituciones modernas cit., págs. 546-570. 
Había soluciones en Derecho para soslayar el problema del referéndum y, al menos, proceder a las otras tres reformas a que se refería el Acuerdo de Consejo de Ministros (es decir, reforma del Senado, reconocimiento de las Comunidades Autónomas y Ciudades Autónomas en el texto constitucional y referencias a la Constitución europea) pero aquí el Informe del Consejo de Estado no contribuyó a resolver el problema pues dictaminó que los cuatro puntos de la reforma propuestos por el Gobierno deberían incorporarse en una decisión única que se tramitaría por un procedimiento único. Más allá de las consecuencias políticas de la recomendación, el Consejo de Estado, desde un punto de vista estrictamente jurídico, dio una interpretación excesivamente rígida. El intérprete ha de proporcionar a su «cliente» todas las soluciones posibles en Derecho y la propuesta de una decisión única y de un procedimiento único dificultaba la tramitación de la reforma. Nada impedía que el Gobierno, que es el dueño de la reforma hasta que se formaliza la iniciativa ante las Cortes Generales, desglosara su iniciativa. Es posible que ello tampoco hubiera facilitado la reforma, por las razones que hemos visto más arriba, pero en todo caso era una fórmula posible que el Consejo de Estado, con un enfoque académico y rígido, no se planteó. ${ }^{28}$

iii) La coincidencia del debate con la reforma del Estatuto de Cataluña. Aunque se trataba de procesos normativos no conectados, es posible que el intenso debate político que suscitó la aprobación del nuevo Estatuto de Autonomía de Cataluña mediante la Ley Orgánica 6/2006, de 19 de julio, quizá restara fuerzas a la reforma constitucional. Se ha dicho también, como veremos a continuación, que las reformas estatutarias emprendidas en otras Comunidades Autónomas iban en dirección opuesta al Informe del Consejo de Estado pero en todo caso, la tramitación conflictiva fue la del nuevo Estatuto catalán. Aquí nos limitamos a evocar este tema porque habría que hacer un análisis mucho más profundo y documentado pero es posible que sin el gran debate del Estatuto catalán hubiera habido más sosiego para plantear las consecuencias de la reforma constitucional.

Como acabamos de decir, algún autor considera que el Informe del Consejo de Estado no satisfizo al Gobierno porque proponía aclarar los elementos esenciales del Estado autonómico en un momento en que las reformas estataturias iban por otra dirección y que por eso quedó arrumbada la reforma ${ }^{29}$. Es posible que esa circunstancia influyera, como también quizá influyó la incomprensible tardanza de once meses en emitir un Informe de 359 folios de letra de gran tamaño. Pero creo que los motivos sustantivos fueron la tardía constatación de la falta de apoyo del Partido Popular y el temor al referéndum, máxime cuando, como hemos visto, el Consejo de Estado no tuvo la flexibilidad de sugerir dos procesos de reforma diferentes.

Se constata así que lo determinante de la reforma no es el procedimiento sino la implicación política de los partidos. El método de preparación de la reforma a través del Consejo de Estado fue erróneo, por inexperiencia o por ingenuidad, pero la reforma, antes de llegar al Consejo de Estado, estaba bastante condenada porque el principal partido de la oposición no la asumía ni, parece, el Gobierno intentó establecer un diálogo so-

28 Véase el ingenioso pero no menos inteligente trabajo de Francisco LAPORTA «Las dos vías para la reforma de la Constitución», Clones de Razón Práctica, n 154, septiembre 2004, págs. 14-23. Fue el primer autor que planteó los problemas de la reforma y las vías para soslayarlos.

29 Luis María DÍEZ-PICAZO: «Prólogo» cit., pág. 14. 
bre este punto. Una cosa es apoyarse en el Consejo de Estado y otra distinta negociar, o no negociar, con todos los partidos de la oposición.

\section{ENTRE UNA REFORMA CONSTITUCIONAL FRACASADA Y UNA REFORMA CONSTITUCIONAL IMPREVISTA. II. LO IMPREVISTO ${ }^{30}$}

La segunda parte de este pequeño fragmento de la más reciente historia constitucional española concluye de manera antitética a la primera que acabamos de ver. El 23 de agosto de 2011 se celebró una sesión plenaria extraordinaria del Congreso de los Diputados para convalidar un Decreto-Ley, el Real Decreto-Ley 9/2011, de 19 de agosto, de medidas para la mejora de la calidad y cohesión del Sistema Nacional de Salud, de contribución a la consolidación fiscal, y de elevación del importe máximo de los avales del Estado para $2011^{31}$. La defensa de esa convalidación correspondería a la Ministra de Economía y Hacienda, máxime cuando también era Vicepresidenta del Gobierno. Pero quien defendió la convalidación fue el Presidente del Gobierno, Rodríguez Zapatero. Su discurso apenas trató del Decreto-Ley ${ }^{32}$ sino que dedicó casi todo el tiempo a describir la gravedad de la situación económica y acabó proponiendo reformar la Constitución para incluir mecanismos de estabilidad presupuestaria. Dada la importancia del tema, propuso que la reforma se efectuara por iniciativa parlamentaria e informó a la Cámara que ya había hablado del tema con el Presidente del Partido Popular como primer partido de la oposición (Rajoy) y con el candidato del PSOE a las próximas elecciones (Pérez Rubalcaba) ${ }^{33}$. En su intervención, el Presidente del Partido Popular informó que su Grupo Parlamentario estaba dispuesto a facilitar la tramitación de la reforma constitucional y a apoyarla. Rajoy afirmó también que desde hacía más de un año estaba solicitando la adopción de una medida similar ${ }^{34}$.

A partir de ese debate se fue concretando que la reforma afectaría al artículo 135 de la Constitución. El texto de la reforma se confeccionó con tanta rapidez que tres días después de la propuesta del Presidente Rodríguez Zapatero, el 26 de agosto, se publicó en el Boletín

30 Sobre la reforma constitucional de 2011 la aportación más completa es la de Teoría y Realidad Constitucional, $\mathrm{n}^{\circ} 29,1^{\circ}$ semestre 2012, dedicado monográficamente a «La reforma constitucional». Además, Roberto Luis BLANCO VALDÉS: «La reforma de 2011: de las musas al teatro», Claves de Razón Práctica, n 216, octubre 2011, págs. 8-18; Javier TAJADURA TEJEDOR: «Reforma constitucional e integración europea», Claves de Razón Práctica, no 216, octubre 2011, págs. 20-29; Lorenzo MARTíN-RETORTILLO: «La reforma de la Constitución: una llamada a la responsabilidad», Revista Española de Derecho Administrativo, $\mathrm{n}^{\circ} 153$, enero-marzo 2012, págs. 11-14; Jorge GARCÍA-ANDRADE GÓMEZ: «La reforma del artículo 135 de la Constitución española», Revista de Administración Pública, n 187, enero-abril 2012; Miguel Ángel MARTÍNEZ LAGO: «Crisis fiscal, estabilidad presupuestaria y reforma de la Constitución», El cronista del Estado Social y Democrático de Derecho, n 24, diciembre 2011, págs. 10-21; Ignacio GORDILLO PÉREZ: «A propósito de la reforma constitucional de 2011», El cronista del Estado Social y Democrático de Derecho, no 25, enero 2012, págs. 31-37; y Álvaro RODRÍGUEZ BEREIJO: «La reforma constitucional del art. 135 CE y la crisis financiera del Estado», Otrosí. No 11, julio-septiembre 2012, págs. 7-16.

31 DSCD. Pleno y Comisión Permanente. IX Legislatura. No 268. 2011. Sesión plenaria nº 254 (sesión extraordinaria) celebrada el martes 23 de agosto de 2011.

32 Cuyo título no parecía cumplir las instrucciones gubernamentales sobre concisión en los títulos de las Leyes.

33 DSCD, cit. (23 de agosto de 2011), pág. 5.

34 DSCD, cit. (23 de agosto de 2011), págs. 5-6. 
Oficial de las Cortes Generales como proposición de reforma conjunta de los Grupos Parlamentario Socialista y Popular ${ }^{35}$. El 30 de agosto el Congreso de los Diputados debatió la toma en consideración (318 votos a favor, 16 en contra y 2 abstenciones) y el acuerdo de tramitación rápida y en lectura única (319 votos a favor y 17 en contra). A pesar del ofrecimiento del Presidente Rodríguez Zapatero a todos los Grupos Parlamentarios, parece que en ese debate liminar los dos partidos proponentes no hicieron muchos esfuerzos por consensuar la reforma y ni siquiera se intentó con dos Grupos Parlamentarios que participaron en la Ponencia Constitucional (Convergència i Unió e Izquierda Unida). Tampoco se aceptó modificar los plazos para negociar enmiendas con otros Grupos Parlamentarios. ${ }^{36}$

Iniciada la tramitación ${ }^{37}$, la Mesa del Congreso acordó el 30 de agosto establecer un plazo de enmiendas que finalizaba el 1 de septiembre, es decir, se otorgaban unas cuarenta y ocho horas para presentar enmiendas a una reforma constitucional de elevado contenido técnico. ${ }^{38}$ El 2 de septiembre se celebró la sesión plenaria de aprobación de la reforma. Previamente se sometieron a votación dieciséis enmiendas, ninguna de las cuales fue aprobada $^{39}$. La votación final de la reforma dio 316 votos a favor y cinco en contra pues un grupo de Diputados se ausentó antes de la votación en disconformidad con el procedimiento ${ }^{40}$.

El 6 de septiembre de 2011, la Comisión Constitucional del Senado debatió la proposición de reforma constitucional, rechazó todas las enmiendas presentadas y aprobó el dictamen por 23 votos a favor y uno en contra ${ }^{41}$. Como la urgencia seguía siendo extrema, el Pleno del Senado celebró su sesión al día siguiente, el 7 de septiembre. En esta sesión plenaria se debatieron y votaron las enmiendas, que fueron todas rechazadas y se votó el dictamen de la Comisión Constitucional que fue aprobado por 233 votos a favor y 3 en contra. ${ }^{42}$

Transcurrido el plazo de quince días que el artículo 167.3 de la Constitución contempla para que una décima parte de los miembros de cada Cámara soliciten someter a referéndum la reforma constitucional, y sin que llegara a presentarse esa solicitud, la reforma constitucional se publicó y entró en vigor el 27 de septiembre de 2011.

35 BOCG. CD, serie B, no 329-I, 26 de agosto de 2011.

36 DSCD. Pleno y Comisión Permanente. IX Legislatura. N No 269. 2011. Sesión plenaria no 255 (sesión extraordinaria) celebrada el martes 30 de agosto de 2011.

37 Sobre los numerosos problemas procedimentales de la tramitación, Piedad GARCÍA-ESCUDERO MÁRQUEZ: «La acelerada tramitación parlamentaria de la reforma del artículo 135 de la Constitución (Especial consideración de la inadmisión de enmiendas. Los límites al derecho de enmienda en la reforma constitucional)», TRC, nº 29, 2012, págs. 165-198; María Josefa RIDAURA MARTÍNEZ: «La reforma del artículo 135 de la Constitución española: ¿pueden los mercados quebrar el consenso constitucional?», TRC, n 29, 2012, págs. 237-260; Elviro ARANDA ÁLVAREZ: «La "sustancialidad” del procedimiento para la reforma constitucional», TRC, n 29, 2012, págs. 389-408; y Octavio SALAZAR BENÍTEZ: «La Constitución domesticada. Algunas reflexiones críticas acerca de la reforma del artículo 135 CE», TRC, n 29, 2012, págs. 409-432.

38 El Acuerdo de la Mesa se publicó en BOCG. CD, serie B, n 329-2, 31 de agosto de 2011.

39 La extrema urgencia en la tramitación provocó que las enmiendas se publicaran con posterioridad a su rechazo (BOCG. CD, serie B, no 329-3, 5 de septiembre de 2011)

40 DSCD, Pleno y Comisión Permanente. IX Legislatura. $N^{\circ} 270.2011$. Sesión plenaria no 256 celebrada el viernes2 de septiembre de 2011.

41 DSS. IX Legislatura. No 561.6 de septiembre de 2011. Comisión constitucional celebrada el martes 6 de septiembre de 2011.

42 DSS. IX Legislatura. N 130. Pleno. Sesión celebrada el miércoles 7 de septiembre de 2011. 
Hemos descrito prolijamente este iter de reforma porque, más allá del contenido de la reforma, que no es pacífico en el mundo político ni en el mundo académico, lo que más llama la atención es la urgencia de la tramitación y la paralela negativa a todo diálogo o negociación con los Grupos Parlamentarios distintos de los dos que presentaron la iniciativa. Pero antes de sacar alguna consecuencia de este fenómeno de urgencia y falta de negociación conviene señalar que una reforma constitucional de este cariz no es una rareza en el Derecho comparado.

El ejemplo más citado, por su semejanza, es la Ley francesa de 10 de agosto de 1926 de revisión parcial de la Ley constitucional de 25 de febrero de 1875 relativa a la organización de los poderes públicos. Como se sabe, la Tercera República francesa no se dotó de una Constitución sino de tres Leyes constitucionales (dos de 25 de febrero de 1875 y otra de 16 de julio del mismo año), que fueron reformadas varias veces. La reforma más peculiar fue, como acabamos de ver, la de 10 de agosto de 1926 que vino a añadir un artículo a la Ley constitucional de 25 de febrero de 1875 relativa a la organización de los poderes públicos. Este precepto nuevo constitucionalizaba la autonomía de la Caja de Gestión de los Bonos de la Defensa Nacional y de Amortización de la Deuda Pública y afectaba a dicha Caja, para fortalecerla, el producto de diversos impuestos. El motivo de esta reforma era la crisis financiera que sufría Francia desde 1924 y que afectaba precisamente a la deuda pública por lo que el Gobierno de Poincaré creó la Caja y la «blindó» constitucionalmente con el voto en contra de socialistas y comunistas ${ }^{43}$. Los constitucionalistas conservadores valoraron la reforma con comprensión: para Barthélemy y Duez la reforma constitucional pretendió solventar un problema político y psicológico y restablecer la confianza en la economía francesa. Desde este punto de vista, decían, la reforma constitucional fue un éxito pues el franco francés recobró parte de su cotización en relación con la libra británica ${ }^{44}$. Tardaría mucho tiempo en reconocerse que la reforma era jurídicamente innecesaria como advirtió $\operatorname{Vedel}^{45}$.Sobra formular comparaciones.

Tras este recorrido procedimental, tres cuestiones se suscitan: i) cómo se originó la iniciativa de reforma constitucional;ii) ¿estaba justificada esa tramitación desde un punto de vista democrático?; y iii) ¿se ha roto el mito de la irreformabilidad de facto de la Constitución?

Aunque no existen evidencias documentales, ciertos trabajos de periodismo de investigación hablan de una carta dirigida por los Gobernadores del Banco Central Europeo y del Banco de España, Jean-Claude Trichet y Miguel Ángel Fernández Ordóñez, al Presidente del Gobierno, Rodríguez Zapatero, donde se exigía al Gobierno español un programa de reformas económicas y sociales muy intenso. Sin ese programa, el Banco Central Europeo no compraría deuda española, precisamente en unos días en que el precio de la deuda estaba elevadísimo y había el riesgo de que se acordara la llamada «intervención» de España. ${ }^{46}$ Parece que ante ese extenso programa de medidas y la amena-

43 Jacques GODECHOT: Les constitutions de la France depuis1789, Garnier-Flammarion, París, 1970, pág. 330.

44 Joseph-BARTHÉLEMY y Paul DUEZ: Traité de Droit constitutionnel, Dalloz, París, 1933, pág. 33.

45 Georges VEDEL: Droit constitutionnel, Sirey, París, 1949, págs. 58-59.

46 Mencionan la carta Mariano GUINDAL y Mar DÍAZ-VARELA: Los días que vivimos peligrosamente. La trastienda de la peor crisis económicaque ha vivido España, Planeta, Barcelona, 2012, págs. 296-297; Ernesto EKAIZER: Indecentes. Crónica de un atraco perfecto, Espasa, Madrid, 2012 pág. 134; y Enric JULIANA: «La "intervención” tomó cuerpo con una carta secreta del BCE», La Vanguardia, 15 de julio de 2012. 
za de intervención, el Presidente Rodríguez Zapatero optó, como Poincaré en 1926, por compendiar en una reforma normativa el espíritu de las medidas a que se comprometía, con el apoyo, que era obligado, del primer partido de la oposición. Así se reformó el artículo 135 de la Constitución.

No vamos a efectuar un análisis de contenido de la reforma, que ya han publicado muchos autores. Tampoco vamos a especular sobre las posibilidades reales que el Gobierno español tenía para soslayar amenazas sin acudir a la reforma constitucional. Pero sí se constata que una medida tan radical (que cerró por completo las posibilidades electorales del PSOE) iba mucho más allá de lo requiere la pertenencia a la Unión Europea.

Por otro parte, si las medidas Trichet/Fernández Ordóñez quebraron la soberanía española ${ }^{47}$, el procedimiento pactado entre el Gobierno, el PSOE y el Partido Popular erosionó el principio democrático. Lo erosionó porque una reforma constitucional aprobada por procedimiento de lectura única, sin negociación con el resto de los Grupos Parlamentarios, incluso sin acudir al Consejo de Estado al que antaño se quiso implicar en las reformas, puede ser formalmente respetuosa con la Constitución pero no lo es materialmente porque, tal como establece el Título $\mathrm{X}$ de ésta, la reforma ha de ser dialogada (exigencia para las dos Cámaras, ex artículo 167.1), participada (por eso las previsiones de referéndum de los artículos 167.3 y168.3) y suficientemente debatida por las Cortes. Nada de eso se hizo y se dio incluso la llamativa publicación de las enmiendas de los Grupos Parlamentarios después de haber sido votadas en contra. Por eso se respetó formalmente el ordenamiento pero no su espíritu, aunque esta falta de respecto no es residenciable en el Tribunal Constitucional.

También hay que decir, como destaca Martín-Retortillo, que la cuasi inaplicada reforma constitucional resulta practicable si se considera necesario y conviene ${ }^{48}$, lo que en un lenguaje más crudo, significa que si los dos grandes partidos nacionales lo acuerdan, habrá reforma constitucional, sin necesidad de acudir al Consejo de Estado.

Sin embargo, queda una duda. Wheare decía que los procedimientos de revisión constitucional perseguían cuatro finalidades: que la Constitución se modifique solamente tras un proceso de deliberación y no a la ligera; que los ciudadanos tengan oportunidad de expresar su opinión; que no se modifique sólo por la acción de un partido; y que se respeten los derechos de las minorías ${ }^{49}$. Ninguna de esas finalidades se ha cumplido en la reforma de 2011 por lo que la reforma puede considerarse políticamente necesaria pero en modo alguno ha reforzado el principio democrático.

\section{IV. ¿SE HA ABIERTO LA POSIBILIDAD REAL DE UNA REFORMA DE LA CONSTITUCIÓN?}

De lo dicho hasta aquí se puede sacar una conclusión: a lo largo del siglo XXI la reforma constitucional ha sido en España un fracaso. Fracasó en la octava legislatura porque

47 María Josefa RIDAURA MARTÍNEZ: «La reforma del artículo 135 de la Constitución española: ¿pueden los mercados quebrar el consenso constitucional?» cit.

48 Lorenzo MARTÍN-RETORTILLO: «La reforma de la Constitución: una llamada a la responsabilidad» cit., pág. 12 .

49 C. WHEARE: Las Constituciones modernas cit., pág. 89. 
no logró que se pusiera en marcha la iniciativa que intentó el Gobierno. Fracasó en 2011 porque si bien logró reformar un precepto, se hizo por presiones exteriores y sin posibilidad de debate. Pero la Constitución, más que nunca, necesita una reforma, con alcance incluso más amplio del que el Gobierno propuso en 2005.

Hace falta esa reforma porque:

i) Se habia creado la falsa idea de que la Constitución es técnicamente irreformable. Como acabamos de ver, esto no es así pues una parte importante de los preceptos constitucionales de más conflictividad política (las Comunidades Autónomas, el Senado, etc.) podría haberse reformado con relativa facilidad.

ii) Se ha imposibilitado la modernización del régimen jurídico de la Corona y de los derechos y libertades. El Poder Constituyente quiso proteger de manera especial a la Corona pero el resultado ha sido exactamente el contrario: la regulación vigente impide modernizar este órgano constitucional (preeminencia del varón sobre la hembra en la sucesión) y lo sitúa en la posición arriesgada que comporta siempre en Europa un referéndum sobre la forma de gobierno. Lo mismo puede decirse de la regulación de los derechos y libertades que no pueden modernizarse tras una larga experiencia constitucional por lo que los elementos básicos de su régimen han acabado deferidos a la jurisprudencia constitucional, como veremos a continuación.

iii) Ha desplazado al Tribunal Constitucional el desarrollo efectivo de varios grandes bloques de materias constitucionales. En concreto, el régimen autonómico, los derechos y libertades y las relaciones del propio Tribunal con el Poder Judicial, al no haberse reformado la Constitución por vías ordinarias, han acabado recibiendo una orientación nueva, más rica y más sutil, a través de la jurisprudencia del Tribunal Constitucional. Pero esto no es política ni jurídicamente adecuado. En primer lugar porque dos bloques normativos tan potentes como el régimen autonómico y los derechos y libertades no pueden pender de la continua interpretación del Tribunal Constitucional, que a lo sumo es legislador negativo. Esos dos bloques normativos han de ser regulados sin estridencias por las Cortes Generales a partir de las nuevas previsiones constitucionales. En segundo lugar porque, por razones conocidas, el Tribunal Constitucional ha entrado desde unos años en una dinámica de conflicto, de politización y hasta de deslegitimación y, por ello, no parece, al día de hoy, el órgano idóneo para cerrar la regulación de importantes materias constitucionales.

Todo ello conduce a una conclusión. Ya que los dos grandes partidos nacionales pudieron entenderse en 2011, es un deber para ambos negociar una reforma que, además, no excluya a los partidos nacionalistas. En medio de la crisis económica no se pueden desviar esfuerzos pero la crisis acabará algún día y conviene estar preparado para entonces.

$$
\text { *** }
$$

TITLE: Possible constitutional reforms and impossible constitutional reforms. Notes prior to the reform of the Constitution

ABSTRACT: This article contrasts the project of constitutional reform that the Government submitted to the State Council to be reported in 2005 with the constitutional reform of 2011. The causes of the failure of 2005 attempt and the brief procedure of 2011 are analyzed. Some reasons to initiate a deeper constitutional reform are advanced. 
RESUMEN: Este artículo contrapone el proyecto de reforma constitucional que el Gobierno sometió a informe del Consejo de Estado en 2005 con la reforma constitucional de 2011. Analiza las causas del fracaso del intento de 2005 y el fugar procedimiento de 2011. Acaba avanzado algunas razones para iniciar una reforma constitucional de más calado.

KEY Words: Constitution. Constitutional reform. Constitutional Rigidity. Article 135.

Palabras Clave: Constitución. Reforma constitucional. Rigidez constitucional. Artículo 135.

FECHA DE RECEPCIÓN: 12.06.2012 FECHA DE ACEPTACIÓN: 19.07.2012

UNED. Teoría y Realidad Constitucional, núm. 30, 2012, pp. 301-314. 